\title{
EMPRÉSTIMOS LINGUÍSTICOS E CODE-SWITCHING EM AKWẼ XERENTE/ PORTUGUÊS: CONTRIBUIÇÕES PARA A SOCIOLINGUÍSTICA, PARA A EDUCAÇÃO INDÍGENA E PARA O POVO AKWẼ*
}

RoDRIGO MESQUITA**

\section{RESUMO}

Este artigo analisa a ocorrência de empréstimos linguísticos e code-switching na comunidade de fala Akwẽ-Xerente (Jê), considerando seus aspectos linguísticos e extralinguísticos. Os fenômenos de contato são analisados à luz da Etnografia da Fala (HYMES, 1972), do modelo 4-M (MYERS-SCOTTON; JAKE, 2000), do Markedness Model e do MLF, elaborados por Myers-Scotton (1993a; 1993b; 2002). As análises apontam o comportamento dos fenômenos sensíveis às variáveis sociolinguísticas e eventos de fala identificados. Também são orientadas no sentido de sua contribuição para as ciências da linguagem, para a reflexão crítica do povo Xerente sobre sua própria realidade e para a educação indígena.

PalaVRas-Chave: Sociolinguística, Língua Akwẽ Xerente, Língua portuguesa, Code-switching, Educação indígena

\section{INTRODUÇÃO}

O bi/multilinguismo é um fenômeno decorrente do contato entre povos e, consequentemente, das línguas por eles faladas. As características das línguas, seus usos e as motivações extralinguísticas

* Este artigo faz parte do Projeto Liba: línguas indígenas brasileiras ameaçadas de extinção: documentação (análise e descrição) e tipologias sociolinguísticas e do Grupo de Educação e Línguas Indígenas da Universidade Federal de Goiás (UFG), coordenados por Silvia Lucia Bigonjal Braggio.

** Doutor em Letras e Linguística pela Universidade Federal de Goiás (UFG), Goiânia, Goiás, Brasil. Professor adjunto na Universidade Federal de Roraima (UFRR), Boa Vista, Roraima, Brasil. E-mail: rodrigomesquitago@hotmail.com 
subjacentes podem ser entendidos, portanto, dentro de um cenário mais amplo, compreendido pelo contexto sócio-histórico e cultural e que se materializa nas atualizações linguísticas realizadas pelos falantes.

Algumas dessas atualizações, caracterizadas pela mescla ou alternância entre as línguas, compreendem fenômenos identificados e conceituados pela sociolinguística, ou mais especificamente, pelos estudos de línguas em contato. Como são variados os conceitos, contextos e concepções e, por isso, obscurecidas as conexões e fronteiras entre esses fenômenos, procuramos ir além das conceituações para investigar os meios e motivos pelos quais a alternância de línguas - ou como convencionamos nesta comunicação, o code-switching ou simplesmente CS - e os empréstimos linguísticos são amplamente utilizados em um determinado contexto sociocultural. Mais especificamente, investigamos as motivações intra e extralinguísticas atuantes no contato entre as línguas Xerente e portuguesa, utilizadas pelos indivíduos bilíngues indígenas da comunidade de fala Akwẽ Xerente.

A análise dos aspectos linguísticos do CS entre o par de línguas, como veremos, fornece importantes dados para a ciência linguística na medida em que registra ocorrências de configurações entre gramáticas de línguas tipologicamente distintas pouco identificadas na literatura internacional, tampouco no contexto brasileiro. As motivações sóciopragmáticas do CS, por sua vez, analisadas em conjunto com a realidade sociolinguística e cultural do povo Xerente - marcada por assimetria política e econômica e consequentes conflitos diglóssicos quanto às funções sociais desempenhadas pelas línguas - são relacionadas com o processo de obsolescência da língua indígena alertado por Braggio $(1997 ; 2005 ; 2012)$.

O amplo entendimento dos fenômenos de contato pode, neste sentido, fornecer valiosos subsídios para as políticas linguísticas de afirmação, fortalecimento, valorização e (re)vitalização da língua e cultura Xerente. Além disso, também oferece subsídios para a educação (escolar) indígena, já que torna possível o entendimento das demandas e funções sociais desempenhadas pela língua Xerente e pelo português, premissa básica para a proposta de uma educação bilíngue mais responsável e comprometida linguística e culturalmente. 
Sob esta perspectiva, apresentamos inicialmente uma breve contextualização histórica do contato Xerente com a sociedade não indígena; em seguida expomos as bases teóricas e metodológicas que orientam as análises; finalmente, discutimos os aspectos linguísticos e extralinguísticos do contato entre a língua Xerente e o português como foco no code-switching, assim como as contribuições para as ciências da linguagem, a educação indígena e o povo Akwẽ-Xerente.

\section{A históRIA do CONTATO E A ATUAL SITUAÇÃo SOCIOLINGUístiCA}

A breve contextualização sócio-histórica do contato do povo Xerente com os não indígenas, busca levar à compreensão do atual quadro sociolinguístico dos indígenas, marcado pela situação de contato assimétrico com a sociedade majoritária. Tal quadro será fundamental para compor as noções de comunidade de fala e evento de fala (HYMES, 1972), cunhadas pela Etnografia da Fala e utilizadas neste trabalho. Isso inclui o conhecimento de fatos históricos, da organização social e das consequências da aceleração do contato nas últimas décadas.

Os Xerente, ou como preferem, Akwẽ ("gente importante", "gente mesmo"), vivem em diversas aldeias (aproximadamente 70) espalhadas pelas terras indígenas Xerente e Funil. Essas terras estão entre os municípios tocantinenses de Pedro Afonso, Rio Sono, Lageado e Tocantínia. Neste último está a maior concentração de indígenas Xerente fora das aldeias (aproximadamente $10 \%$ da população). As estradas que ligam os municípios cortam as terras indígenas. A ligação desses municípios a Palmas, capital do estado, se dá por essas estradas. Nelas, também transitam os mais de 3.500 indivíduos indígenas que buscam nos centros urbanos, além dos insumos industrializados e tecnológicos que caracterizam o modo de vida contemporâneo, assistência à saúde e educação. Buscam ainda os alimentos que já não se encontram de forma farta e disponível para coleta na região de cerrado constantemente castigada pelas queimadas, mais densamente ocupada, persistentemente invadida e cercada por áreas desmatadas para as lavouras de cana-de-açúcar, milho, soja e sorgo.

Nessa região também brota o capim dourado e a tiririca, matériasprimas para o conhecido artesanato Xerente, uma das fontes de renda 
das famílias indígenas. As outras são os cargos públicos efetivos e temporários, empregos no comércio das cidades, aposentadorias e bolsas concedidas pelo governo federal.

Os governos estadual e municipal constantemente distribuem cestas básicas e são solicitados a contribuírem com transporte e infraestrutura para projetos locais, tais como festas indígenas e outros eventos, com a prerrogativa do "incentivo à cultura". Tais esferas do governo também são responsáveis pela educação escolar indígena e tem com os órgãos do governo federal uma parceria para o atendimento à saúde do povo Xerente.

A história do contato ${ }^{1}$, iniciada no século XVII e marcada pelo quase extermínio dos Akwẽ pelas frentes colonizadores até meados do século XX, é parcial. Baseada em registros de viajantes, bandeiras e documentos oficiais ou não dos governantes das então capitanias, a versão acessível é sempre a do não índio. A cultura Xerente, de tradição predominantemente oral, não deixou registros dos conflitos. O que existe, na verdade, são alguns (supostos) relatos de indígenas descritos pelos correspondentes do governo, através de citações livres. Tais documentos relatam os desfechos dos confrontos que se estenderam até 1851, quando os Xerente são aldeados. Depois de se espalharem várias vezes para não serem massacrados, sofrer com epidemias, possíveis contaminações propositadas e com o consequente decréscimo populacional, já no aldeamento Tereza Cristina, "ao contrário de outras nações aniquiladas na região goiana, os Xerente absorvem ativamente a cultura circundante, mas sobrevivem (física e culturalmente)" (GIRALDIN; SILVA, 2002, p. 15).

Com a demarcação das Terras Indígenas Xerente (em 1972) e Funil (em 1988), além das mudanças de perspectiva em relação à questão indígena na Constituição Federal de 1988, os Xerente voltaram a apresentar uma recuperação demográfica e, como não poderia ser diferente, a enfrentar novos desafios. Entre eles, o de reorganizar suas formas de organização social, de estabelecer suas lideranças, relacionarse, comer, utilizar sua(s) língua(s) etc., para que pudessem se adaptar ao novo modo de vida caracterizado pela intensificação do contato.

Essa nova organização social também reagiu à entrada de capital privado, no início do século XXI, advindo, principalmente, 
do projeto para compensação ambiental dos impactos causados pela construção e operação da usina hidrelétrica (UHE) Luís Eduardo Magalhães - Lajeado, no rio Tocantins, entre os municípios de Lajeado e Miracema do Tocantins. O Programa de Compensação Ambiental Xerente (PROCAMBIX) injetou 10 milhões de reais na economia Xerente entre 2002 e 2010 através de convênio envolvendo a INVESTCO S/A e a FUNAI, com interveniência do Ministério Público Federal. Nesse período, os Xerente se dividiram internamente ainda mais, saltando de 35 para 62 aldeias. Algumas consequências que podem ser apontadas (MESQUITA, 2015a) são os conflitos internos motivados pela distribuição assimétrica dos recursos, a mudança de atitude dos indígenas com relação ao ecossistema (como abandono gradativo da agricultura de coivara, por exemplo) e as alterações na alimentação e no consumo de demais insumos industrializados, também proporcionados pela implementação da distribuição de energia elétrica nas aldeias.

De forma concisa, a década seguinte - que segue até os dias atuais - é caracterizada pela (re)adaptação do povo Xerente às novas condições socioeconômicas com o fim do PROCAMBIX. Essas condições incluem conflitos com esferas públicas por incompatibilidade de interesses, permanência das desavenças com os proprietários de terras adjacentes às terras indígenas, constante migração para a cidade e intensificação dos conflitos internos e da dependência de recursos externos. Algumas mudanças já podem ser observadas nesse contexto. Entre elas, para dar um exemplo, estão mudanças na organização social ao alterar o perfil das lideranças, que cada vez mais são delegadas aos jovens (e mais escolarizados) que possuem maior capacidade de articulação com os não indígenas para "competir em pé de igualdade entre o índio e o branco" (SEDUC-TO, 2012). Neste sentindo, os mais velhos e menos escolarizados já não atendem mais ao perfil de liderança ativa, cabendolhes mais frequentemente a posição de conselheiros e intermediadores de conflitos internos.

O contexto sociocultural brevemente descrito ajuda a compreender as características da comunidade de fala Xerente, conceito que esclarecemos melhor em seguida, juntamente com a postura metodológica e a orientação teórica deste trabalho. 


\section{ORIENTAÇÃO TEÓRICA E METODOLÓGICA}

A etnografia da fala (HYMES, 1972) guiou o trabalho de campo, a coleta, organização e tratamento dos dados utilizados na pesquisa. De forma concisa, essa perspectiva teórica inclui a consideração do contexto no estudo de um evento de fala, momento em que dois ou mais indivíduos se comunicam em ocasiões ou aspectos de atividades sociais por sua vez governadas por regras ou normas socioculturalmente definidas pela comunidade de fala. Esta é, por sua vez, heterogênea (um indivíduo pode participar de diferentes comunidades de fala e uma comunidade de fala por conter outras) e caracterizada como um todo organizado por normas compartilhadas social e culturalmente, que regulam as diferentes situações e eventos comunicativos.

Em outras palavras, a etnografia da fala de Hymes (1972) propõe a delineação de métodos e conceitos para a observação etnográfica e análise (êmica e ética) dos hábitos comunicativos e comportamento culturais compartilhados por uma comunidade - a comunidade de fala. Uma exposição detalhada sobre a metodologia e o corpus da pesquisa pode ser encontrada em Mesquita (2015a). Para os propósitos deste artigo, utilizamos recortes de eventos de fala envolvendo indivíduos de diferentes faixas etárias, sexo, nível de escolaridade, em diferentes ambientes (aldeias e cidade) e sobre tópicos variados.

Os eventos considerados de fala foram, de acordo com a organização sociocultural Xerente, ambiente familiar, ambiente público na cidade, atividades esportivas, discursos públicos das lideranças, conversas públicas no rádio amador e discursos dos anciãos e falas rituais. As faixas etárias: a) +jovens (12 a 20 anos); b) \pm jovens (21 a 49 anos) e c) +velhos (50 anos ou mais). Os dados de fala natural coletados em situações comunicativas não controladas, entre 2011 e 2015, foram transcritos conforme a proposta ortográfica de Krieger e Krieger (1994) para a língua Xerente. Para o português, utilizamos a ortografia padrão com aproximação à produção fônica² .

Uma definição abrangente para o CS considera "o uso alternado de dois ou mais códigos por indivíduos bilíngues numa mesma interação conversacional" (GROSJEAN, 1982, p. 145-146). Essa definição, no entanto, não é suficiente para distinguir o CS de outros fenômenos de contato, tais como o empréstimo linguístico. Autoras como Gardner- 
Chloros (2009) e Bullock e Toribio (2009) apontam diversos critérios para essa distinção, tais como categoria gramatical, deslocamento de sinônimos na língua nativa e integração morfofonêmica com a língua envolvente, entre outros.

Por haver lacunas em todas as tentativas e por concordar com Gardner-Chloros (2009) sobre a impossibilidade de formas confiáveis de distinguir os fenômenos sincronicamente ${ }^{3}$, concordamos com a afirmação de Myers-Scotton (1993a), para quem o CS deve ser analisado como um continuum juntamente ao empréstimo, uma vez que seguem em princípio as mesmas regras, ou seja, geralmente estão sujeitos aos mesmos procedimentos morfossintáticos durante a produção da linguagem.

Braggio (1997, p. 160) afirma que "comunidades que utilizam duas línguas no seu cotidiano, não só mudam de código no seu discurso, como emprestam de uma língua para outra por razões linguísticas e extra-linguísticas". Para a compreensão ampla dos fenômenos entre as línguas Xerente e portuguesa, foram combinados três modelos teóricos complementares entre si: o Markedness Model, o Matrix Language Frame Model (MLF) - ambos de Myers-Scotton (1993a, 1993b, 2002) - e modelo dos 4-M (MYERS-SCOTTON e JAKE, 2000; MYERSSCOTTON, 2002).

O primeiro, o Modelo de Marcação (Markednnes Model) de Myers-Scotton (1993b) consiste em um modelo teórico voltado à explicação das motivações sociopsicológicas do CS que são refletidas através de estratégias interpessoais na marcação (ou não) dos códigos linguísticos. Baseada no princípio cooperativo de Grice (1975 apud MYERS-SCOTTON, 1993a), a autora utiliza o princípio da negociação para explicar as escolhas que os falantes fazem enquanto alternam os códigos, considerando as motivações dos falantes e a negociação de identidades num determinado evento de fala. Dessa forma, os falantes possuem uma espécie de senso, que os orienta a interagir com os demais na comunidade de fala da forma não marcada e leva em consideração todas as circunstâncias dos eventos comunicativos, confirmando assim as expectativas dos interlocutores. Já na opção pela forma marcada, será necessária uma negociação contínua entre os interlocutores, no sentido de atribuir funções a cada código, podendo inclusive fazer uso de CS para encontrar a língua comum em meio à situação na qual ocorre o 
evento de fala. Conforme Myers-Scotton (1993b), uma premissa do Modelo de Marcação se baseia no fato de que a escolha de determinado código é modificável, dinâmica e circunstancial, o que explica a escolha da Etnografia da Fala para observação dessas instâncias.

O segundo modelo, também conhecido por MLF, fornece instrumental teórico para analisar a interação entre as gramáticas das línguas em contato no code-switching intrassentencial, sob o argumento de que a distribuição das línguas envolvidas é assimétrica (MYERS-SCOTTON, 1993a). No MFL, uma das línguas envolvidas cede o sistema morfológico e suas categorias funcionais (língua matriz ou ML), constituindo o quadro no qual os elementos da outra língua (língua encaixada ou EL) podem se integrar. A identificação da ML pode ser feita a partir do reconhecimento, na CP bilíngue (ou projeção do complementizador, estrutura sintática que expressa a estrutura predicado-argumento, estabelecida como unidade de análise do modelo), da língua responsável pela cessão do quadro gramatical no qual a outra língua deverá se encaixar. Da ML também vêm os "morfemas gramaticais críticos" que, conforme Myers-Scotton (2002, p. 59), são "morfemas de sistema que apresentam relações gramaticais externas ao seu constituinte núcleo".

Dentro desse modelo, são constituintes possíveis, portanto, as ilhas de $M L$ (contendo apenas morfemas da ML), ilhas de EL (apenas morfemas da EL) e constituintes mistos, incluindo morfemas da ML e EL. Ainda que voltado para uma análise gramatical, o MLF é complementar ao Modelo de Marcação se consideramos os fatores sociolinguísticos operantes sobre a predominância da ML, que geralmente coincide com a primeira língua (L1) do falante e da comunidade de fala (MYERS-SCOTTON, 1993b). Da mesma forma, fatores sociopolíticos, educacionais, situacionais, entre outros, podem influenciar na flutuação da ML e uma possível conversão da L1 em EL.

Complementar ao MLF, o 4-M é um modelo de classificação de morfemas que deve aplicar-se à linguagem em geral (MYERSSCOTTON e JAKE, 2000; MYERS- SCOTTON, 2002), ou seja, sua aplicação é estendida a outros fenômenos de contato e dados linguísticos de natureza diversa. No modelo, morfemas são classificados em termos de suas funções sintáticas empiricamente evidentes, bem como hipóteses 
sobre como eles são ativados na produção de linguagem. Assim, existem quatro tipos de morfemas: morfemas de conteúdo (content morphemes) e três tipos de morfemas gramaticais (system morphemes). São eles os morfemas gramaticais precoces (early system morphemes ou ESM) e morfemas gramaticais posteriores (late system morphemes ou LSM), que se subdividem em dois tipos: ponte (bridge ou BLSM) e exteriores (outsider ou OLSM). São esses últimos os "morfemas gramaticais críticos" (MYERS- SCOTTON, 2002) relacionados com a identificação da ML. Como no modelo MLF, morfemas de conteúdo atribuem e recebem papéis temáticos. Neste aspecto, eles continuam a divergir de todos os morfemas gramaticais.

A breve explicitação dos modelos teóricos não contempla a complexidade dos mesmos ${ }^{4}$. No entanto, faz-se coerente com as análises propostas neste trabalho. Essas vão em direção às contribuições que o entendimento do funcionamento do CS (e empréstimos) na comunidade de fala Akwẽ-Xerente pode proporcionar. É o que passamos a fazer.

\section{Contribuições Para as CiÊNCIAS da linguagem: a INTERAÇão ENTRE GRAMÁTICAS DE LÍNGUAS TIPOLOGICAMENTE DISTINTAS}

As línguas em contato, Xerente (família linguística Jê, tronco Macro-Jê) e (a variedade do) português, possuem diferentes organizações sintáticas quanto à ordem predominante dos constituintes e são, portanto, tipologicamente distintas. A língua do povo Akwẽ é predominantemente SOV (esquema com núcleo final) enquanto o português é predominantemente SVO (núcleo inicial). Apesar das opiniões divergentes ${ }^{5}$, isso implica em uma série de tendências e restrições sintáticas amplamente estudadas pela Linguística descritivista. Algumas tendências também podem estar relacionadas com características comuns às línguas, como por exemplo, o fato de que, em ambas, o sujeito precede o objeto e que, morfologicamente, são línguas sintéticas (ou seja, com maior complexidade da sua flexão em oposição às línguas analíticas).

Pensando nas configurações tipológicas das referidas línguas em particular, aplicamos algumas análises recorrentes que foram realizadas em outros pares de línguas com tipologias diversas. Dentre as análises, 
alguns dados apresentaram comportamento pouco comum entre tais estudos. Colocamos o foco em alguns deles.

Belazi et al. (1994 apud CALLAHAN, 2004, p. 49) afirmam que o complementador deve estar na língua da sentença que o complementa. Assim, não deveria haver CS entre esses termos, como demonstra o exemplo:

(1)

nu é possivi nõkwa ai-m-ba kõ!

não é possível alguém 2-DAT ${ }^{6}$-dançar não

'Não é possível (que) alguém não dança'!

A língua Xerente não possui um equivalente direto ao complementador que do português. No entanto, a língua oferece outros recursos para estabelecer a relação de subordinação em que uma frase complementa o verbo da oração principal. No exemplo (1), o complementador é suprimido no limite do switch entre a oração principal - em português - e a oração subordinada - em Xerente, satisfazendo assim à restrição. Já em (2) e (4), temos exemplos que parecem contrariar a restrição. $\mathrm{O}$ complementador está em português seguido por uma locução verbal Xerente que introduz o complemento da oração principal. Em (3), o mesmo falante utiliza o CS primeiramente satisfazendo à restrição e, em seguida, quando repete a pergunta a seu interlocutor, a viola.

(2)

eu acho qui mãr kõdi akwẽ tkai. n-ĩm-aula psã pe(s).

eu acho que ter/existir NEG gente/índio terra R3-NGR-aula ver certo 'Eu acho que não há (não tem) na terra do akwẽ. (é necessário) confirmar essa aula'.

(a) intão você mim considera qui eu $w a(\mathrm{du})$ re wapte-mre.

$$
1 \text { ainda jovem-DIM }
$$

'Então você considera que eu ainda (sou) jovenzinho'.

nanẽ?

'Como?' 
(b) você mim considera qui watô (du)re wapte-mrê.

$1 \mathrm{Ev}$ ainda jovem-DIM

'Você considera que eu sou um jovenzinho ainda'.

tem gente qui waiku kõdi.

conhecer NEG

'Tem gente que não conhece'.

Sobre o assunto, Myers-Scotton (1993a, p. 256) reconhece que há numerosos contraexemplos de dados mostrando a ocorrência de CS entre o complementador e a sentença complementar. Embora a carência de descrições sintáticas da língua Xerente quanto às sentenças complexas não nos permita uma análise mais minuciosa sobre o assunto, acreditamos que temos aqui, pelo menos, mais três contraexemplos. Conforme Myers-Scotton (1993a), os contraexemplos, tanto em número como em variedade, contribuem para qualificar a universalidade implícita das restrições gramaticais.

Outra restrição analisada é quanto à ocorrência de CS entre verbos auxiliares e principais e ainda entre verbos finitos e formas verbais adjacentes no infinitivo. Em nosso corpus, apenas um exemplo parece contrariar a restrição. Como segue, há um switch envolvendo o verbo português 'poder', na forma finita com marca da terceira pessoa do singular, tempo presente do modo indicativo, juntamente ao verbo Xerente mmẽ ('falar') sem qualquer especificador, o que o coloca na forma infinitiva:

[pod(e) mmẽ], mais da-t sazê(i) kõd ĩ-kmã-acompanhãt.

poder.3SING falar mas 3-ERG confiar NEG 1-POSP-acompanhante

'Pode falar, mas ele não me escutou, acompanhante'.

As categorias que especificam o verbo em Xerente são expressas através da expressão TAMP, onde estão marcados o tempo, aspecto, modo e pessoa (SOUSA FILHO, 2007). Assim, há uma diferença fundamental quanto à marcação de tempo nas duas línguas que dificulta 
a correspondência entre formas verbais complexas, mas que proporciona construções em que o tempo é marcado na expressão TAMP e é seguido por um verbo principal em português:

(6)

rऽ ø-za ku tmã arruma.

coisa (TC) 3-FUT CIT ALA arrumar.

'Diz que a coisa vai arrumar'.

Callahan (2004) demostra a possibilidade de ocorrência de CS entre construções verbais complexas em inglês-espanhol com 24 contraexemplos. A autora argumenta sobre a possibilidade de haver um critério relativo à direcionalidade, segundo o qual o padrão espanhol >inglês (16 ocorrências) facilitaria o CS dentro das construções em relação ao padrão inglês $>$ espanhol ( 8 ocorrências). Com apenas um contraexemplo, com $\mathrm{ML}_{\text {português, }}$ podemos afirmar que esta restrição é mais forte no par Xerente-português.

Alguns dados contribuem também para o desenvolvimento específico dos modelos MLF e 4-M. Conforme o Princípio da Ordem dos Morfemas (MYERS-SCOTTON, 1993a), a ML estabelece a ordem dos morfemas em constituintes ML + EL. Myers-Scotton explica que é preciso cautela para não confundir com ilhas de EL os casos onde há uma sequência de dois morfemas da EL cuja ordem dos morfemas é determinada pela ML. A autora assume que estes casos são raros, como nos exemplos:

\section{(7)}

ta-nõri diret capim-zô knõm.

3-NSG direto capim-POSP andar (NSG)

'Eles andam direto (constantemente) por capim'.

carregadô, [ø-za nõkwa sda kmẽ kâ pilha carregá-ze].

carregador 3-FUT alguém INCOA PARTT pegar (comprar) pilha carregar-NMZ

'Carregador, alguém vai comprar carregador de pilha'. 
(9)

ø-te convidá kõda [mãto n-ĩ-convidá telêfoni-hawi].

3-ERG convidar NEG-NEG 3PAS.PERF R1-?-convidar telefone-POSP

'Convidou sim. (Ele) convidou pelo telefone'.

No exemplo (7), há um advérbio e um nome. Nos exemplos (8) e (9), há um nome e um verbo, nas configurações N-V, N-V e V-N, respectivamente. Nos dois primeiros exemplos, a sentença segue a ordem SOV, com o nome português ocupando a posição de núcleo do complemento verbal. No exemplo (9), a ordem da CP em destaque é SVO, mas tanto o verbo quanto o nome estão marcados por morfemas gramaticais da língua Xerente. Em todos os casos, é visível que a ordem das palavras de uma língua (Xerente, no caso) é imposta aos elementos da outra, resultando assim em constituintes ML + EL e não ilhas de EL. Os dados de Myers-Scotton (1993a) e Callahan (2004) que trabalharam, respectivamente, com os pares swahili-inglês e espanhol-inglês apresentam exemplos semelhantes, porém predominantemente entre nomes e adjetivos. Nossos dados se distinguem por relacionarem outras classes que não estas, uma vez que não há correspondência quanto à classe de adjetivos nas línguas Xerente e portuguesa. As "verdadeiras" ilhas de EL, como explica Myers-Scotton (1993a), são compostas por morfemas da EL dentro de um constituinte ML + EL:

(10)

kũwa wat ĩ-mõr naitê ku (consêlhu da educação indígena)-nã-hã.

DIR 1PAS 1-ir DEM CIT conselho da educação indígena-POSP-ENF

'Eu fui para o conselho da educação indígena'.

Outro ponto que merece destaque diz respeito aos morfemas do tipo ESM (especificadores juntamente aos morfemas de conteúdo, que funcionam como seus núcleos) e BLSM (estabelecem "pontes" entre os elementos que compõem constituintes maiores) encaixados isoladamente, que são considerados mais raros por Myers-Scotton (1993a; 2002) e Callahan (2004), por exemplo. Em nossos dados, há um número bastante considerável de CS com essas configurações. Por 
exemplo, há 32 ocorrências de advérbios em nosso corpus. MyersScotton (1993a) afirma que os advérbios são morfemas gramaticais e que não encontrou registros em seu corpus de ocorrências isoladas em constituintes ML + EL. Seguem alguns exemplos com advérbios da $\mathrm{EL}_{\text {xerente }}\left((11)\right.$ e (12)) e também da $\mathrm{EL}_{\text {português }}((13)$ e (14)):

(11)

então tem qui si apruveitá $p s e ̂ k w a$.

bem

'Então tem que se aproveitar bem'.

pkê ahâmre za si foi.

porque antigamente já se foi

'Por que antigamente (muito tempo atrás), já se foi'.

diret Ø-za ligá.

direto (sempre) 3-FUT ligar

'Direto está ligando (Está ligando constantemente)'.

mais tahã só ĩs(e)nã dupto nẽsi mãt t-simãzus.

mas ele só(mente) verdadeiramente inchar REPET 3.PAS.PERF. 3-pensar 'Mas ele pensou somente em encher (a barriga)'.

A grande maioria dos advérbios da $\mathrm{EL}_{\text {xerente }}$, em ocorrências de code-switching, remetem a noções temporais. Os advérbios da $\mathrm{EL}_{\text {português }}$ $\operatorname{diret}(o)$ e só (que podem ocorrer ocupando outras funções gramaticais) podem, dada a recorrência observada no trabalho de campo, ser interpretados como empréstimos. Essas e outras características do comportamento linguístico dos Xerente, além de precisarem de maior investigação científica, também podem, como se vê adiante, ser levadas para a sala de aula e refletidas pelos próprios Akwẽ. 


\section{Contribuições Para A EDUCAÇÃo INDÍGENA E o POVO AKwẼ}

No atual cenário sociolinguístico e cultural dos Akwẽ, a educação escolar ganha importância maior entre os Xerente quando vista como porta de acesso a melhores condições de vida e de competição no mercado de trabalho. No entanto, a ideia de uma educação indígena diferenciada, que assegura, no artigo 210, capítulo III da Constituição Federal "às comunidades indígenas também [além do português] a utilização de suas línguas maternas e processos próprios de aprendizagem”, ainda não aconteceu efetivamente. Braggio e Sousa Filho (2006) questionam sobre a consideração das epistemologias próprias dos Xerente nos processos de ensino/aprendizagem e a consideração dos conhecimentos (que refletem suas realidades) levados pelos alunos indígenas para sala de aula. Os autores questionam também sobre a utilização da língua indígena nesses processos. Como se tem observado (MELO, 2010; BRAGGIO, 2012; MELO e GIRALDIN, 2012), há uma discrepância entre o discurso da educação diferenciada e a prática das escolas Xerente. A organização, gerência, calendário e conteúdos ainda estão fortemente atrelados ao modelo e à "lógica disciplinadora de formação da escola não indígena" (MELO, 2010, p. 85), ficando restrita ao ensino de língua materna e de arte e cultura a especificidade na qual se baseia a educação escolar indígena do povo Akwẽ.

Ainda assim, há discrepância de opiniões entre pais de alunos, que discordam entre a carga horária destinada ao ensino da língua Xerente em detrimento do tempo destinado ao estudo do português. Para uma parte desses pais, a língua hegemônica deveria ser privilegiada por garantir mais condições de competição com os alunos não indígenas e mesmo os indígenas que vão estudar na cidade (pelos mesmos motivos).

Braggio (2012) relaciona este posicionamento ao processo histórico que insistiu numa educação escolar indígena de base assimilacionista/ integracionista desde a colonização. A imposição do ensino de língua portuguesa durante esse processo e o consequente ocultamento/ deslocamento das línguas indígenas só mais atualmente vem sendo refletido pelos professores que buscam cursos de formação superior para exercício da docência nas escolas indígenas ${ }^{7}$. Apesar de haver estudos sobre o processo de formação desses professores (COTRIM, 2011; 
REZENDE, 2015, entre outros), ainda não há pesquisas mais concretas sobre a atuação deles na educação escolar nas aldeias.

A prática desses professores e professoras, é importante considerar, pois se dá em escolas sucateadas e castigadas por ingerências dos órgãos governamentais envolvidos, muitas vezes com falta de água, de segurança nas instalações, com quantidade de docentes inadequada - além de boa parte com contratos provisórios, o que gera insegurança financeira -, dificuldades no transporte e mesmo a falta de interesse (apontada pelos próprios colegas) de alguns professores, lideranças e profissionais envolvidos na educação escolar indígena (SEDUC-TO, 2012). Desinteresse que pode ser agravado pela falta de materiais e métodos específicos aplicáveis no contexto da escola que norteiem e deem conta do universo singular da cultura Akwẽ.

$\mathrm{O}$ que as propostas atuais concordam é que deve haver um reconhecimento e valorização na prática escolar dos contextos situacionais específicos em que as crianças, jovens e adultos indígenas se encontram. Para Braggio e Sousa Filho (2006, p. 220), "partir do conhecimento que ela adquire dentro desse contexto é, de nosso ponto de vista, a forma mais adequada de se atuar na escola". Um dos entraves para a efetivação dessas propostas é a falta de materiais didáticos que deem suporte a conteúdos, métodos e epistemologias próprias e que considerem tais contextos, incluindo a situação sociolinguística. Essa inclui os usos e funções sociais das línguas, suas características estruturais, variações e processos históricos que condicionam as mudanças e a monitoramento dessas mudanças.

Os Akwẽ-Xerente se encontram em momento de bilinguismo alto, ou seja, a maioria domina a língua indígena e o português (BRAGGIO, 2012). A regra sociolinguística determina que os Xerente utilizem somente a língua indígena na interação com outro Xerente (BRAGGIO, 2005; MESQUITA, 2009; 2015). A pesquisa realizada mostra que os fenômenos empréstimo e code-switching, comuns em contextos bilíngues de contato linguístico e sociocultural, estão presentes no comportamento linguístico dos Xerente, em diversos eventos de fala que vão dos usos mais cotidianos até situações mais formais e/ou específicas. 
A análise realizada, conforme o Modelo de Marcação (MYERSSCOTTON, 1993b) e a Etnografia da Fala (HYMES, 1972), permite afirmar que a língua Xerente é, em geral, a escolha não marcada nos eventos de fala considerados (MESQUITA, 2015a). No entanto, alguns eventos são mais resistentes do que outros ao contato com o português. Os discursos dos anciãos são, de longe, os mais resistentes, com raríssimas inserções, geralmente de empréstimos já consolidados na língua Xerente. Ao contrário, os eventos realizados na cidade e/ou que envolvem assuntos relativos a tal contexto (MESQUITA, 2015a; 2015b), são mais propensos à ocorrência dos fenômenos de contato. $\mathrm{O}$ CS se apresenta como escolha não marcada justamente nestes eventos, ou seja, a própria alternância passa a ser a escolha mais natural, o que configura o português como um índice de um conjunto de atributos que inclui os traços [+educação], [+formalidade], [+autoridade], [+oficial] e [+status sociocultural]. As noções de marcado e não marcado, assim, aplicadas aos códigos de que dispõem os indivíduos na comunidade de fala, são pautadas por avaliações (mesmo inconscientes) dos custos e benefícios das opções e também pelas relações entre os membros da comunidade, o que consideramos coerente com a atual situação sociolinguística dos Xerente, dada as configurações do contato com a sociedade majoritária. $\mathrm{O}$ evento que passamos a analisar exemplifica essas afirmações.

No evento, lideranças estão reunidas em uma espécie de palanque montado na aldeia Brupre, durante as festividades que incluem competições esportivas. Participam cinco homens, sendo quatro \pm jovens e um +velho, que discursam para a mesma plateia (formada por falantes Xerente e poucos não indígenas), distribuídos entre todos os níveis de escolaridade considerados. $\mathrm{O}$ falante $(\mathrm{K})$, que não frequentou a escola, assim como a maioria que se enquadra na mesma situação, é um ancião (+velho). Por um provável reflexo do sentimento de não ter frequentado a escola, se justifica quanto ao seu conhecimento, que considera limitado na concepção dos jovens escolarizados, que eram maioria na plateia para a qual discursava:

$\mathrm{K}$ - are wa (wa)za ĩmrẽm bãkâ nrõwdepisi aimã. ĩptõkda aimõ tânẽ mãri waiku kõ nãre, aimõ tô wapte nõri tkri sãm mnõ zemba, waza 
kanõrĩkwa akwẽ nõrĩ wapte nõrĩ dakmãdkdâkwai nõrĩ. waza tô waite ĩsimãzus ze, aipkẽ kupar nã kba, waza ĩmrẽm.

'E agora eu vou falar da aldeia Nrõwdepisi. Ancião que pouco sei, pelo que os jovens acham de mim, eu vou a todos os akwẽ, todos os jovens, todos os caciques. Eu já vou com meu pensamento, mesmo que vocês não aceitem (lit.: 'longe de vocês'), eu vou falar'.

No ato de fala, há apenas duas ocorrências de CS, ambas com a inserção do conectivo "mai", forma fonética/fonologicamente adaptada da conjunção 'mas':

$\mathrm{K}$ - watô wawẽ nãre mai hatô aikwa nĩkwa wa(h)ã... mai wahã tô amõ tô waikure ku, wahã tô amõ tka ĩtka kukrerê.

'Eu sou velho mais puxo vocês (para dançar), eu... mas eu vou até onde conhecer, eu vou esfregar o chão com meu pé'.

O discurso de $K$ tem tempo (pouco mais de quatro minutos) mais ou menos equivalente ao de $S$, liderança, \pm jovem e com formação superior. No entanto, $S$ faz 38 switches, quatro deles em projeções com $\mathrm{ML}_{\text {português }}$ o que o coloca como o falante com maior variedade de recursos gramaticais no evento, além da alta frequência.

$\mathrm{S}$ - kahã dazakrui ka mõi hawi mã wat nhã wapte kmãdâk. waza agradecê dure tanõri hã dure, amõ nĩ wazu mãra tê kwanĩ zahã. are wapte nõri bât ka aisimã sãm kbanã, kri tôi zaptô bât tê smrãk. wa ĩnmrã kõd, kũwa wat ĩmõr naitê ku conselho da educação indígena-nã hã. tâkanẽ pibumã bukã ãhã, mãri wahu kamõ nã nós qué fazê mais bonita ainda, porque adu kmãstô kõd. kwat, kwat mês kãte adu, wanĩm scor-di tônmẽm hã krãsâpte wamã, escola indígena krasãpte. são kwat o cinco mês mais o meno. tôza wat adu movimento kmãnãiren bât kã, i ano que vem no vamu fazê mais ainda wa(za) kmãnãn zahã, kmãnãn. nós tamos com os braços aberto, qualqué um.. nõkwa aisi zewa pertencê zewa, wanĩm escor krasãpte estamo com braços aberto pra recebê qualqué uns aluno. nõkwa pe kõre desejá wa, wat wê kõ kõdi wanõri, estamos aqui i wa como rowahtukwa... 
'Eu vi alguns jovens que são de outras aldeias. Vou agradecer também a eles, por estarem enfrentando a noite conosco. E os jovens que estão aí de pé, que jogaram bola. Eu não estava. Fui para o conselho da educação indígena. É para isso que, no ano que vem nós queremos fazer mais bonita ainda (a festa), porque não é o fim. Quatro, quatro meses talvez ainda, que nossa escola daqui, Escola Indígena Krasãpte. São quatro ou cinco meses mais ou menos. Mesmo assim estamos fazendo o movimento, e ano que vem nós vamos fazer mais ainda. Nós vamos fazer, fazer. Nós estamos com braços abertos, qualquer um... alguém (quiser) entrar (e) quiser pertencer, nossa Escola Krasãpte, estamos com braços abertos para receber qualquer aluno. Se alguém talvez desejar, nós não rejeitamos, estamos aqui, e eu como professor'...

À medida que percebemos um contexto sociolinguístico e cultural permeado por conflitos diglóssicos oriundos de uma relação assimétrica com a sociedade majoritária e os impactos na organização social, no ambiente em que vivem (e nas formas de se relacionar com ele), na educação indígena e uso das línguas, acreditamos que os resultados apontados nesta pesquisa possam oferecer subsídios para a educação escolar indígena, especialmente para o ensino de línguas. $\mathrm{O}$ fato de que o nível de escolaridade também é diretamente proporcional à ocorrência de fenômenos de contato coloca a escola indígena novamente em posição especial no debate em relação aos programas de educação efetivamente realizados.

Abordados nos materiais didáticos e discutidos nas vivências intra e interculturais, os fenômenos estudados aparecem como elementos para reflexões sociolinguísticas em conexão com seus contextos de produção. Braggio (2012, p. 172), apesar de não se aprofundar no tratamento do CS, considera importante apontá-lo

pois o contato mais intenso com o português pode aumentar o seu uso pelos falantes +jovens em situação de bilinguismo alto. É importante salientar que fazer code-switchings é um processo normal entre bilíngues. Todavia, quando se trata de relação de uma língua forte com outra minorizada, é possível que a L2 domine a L1, acabando por deslocá-la. 
A reflexão proposta pode proporcionar uma atitude positiva dos falantes (principalmente os mais jovens) em relação à língua indígena e a sua consequente (re)afirmação e valorização, além do reconhecimento da(s) variedade(s) do português utilizado pelos Akwẽ. Assim, extrapola os domínios da escola e pode ser refletido por toda a comunidade de fala. Mesquita e Silva (no prelo) mostram, a partir das avaliações e atitudes de jovens Xerente, indícios de que há uma consciência etnolinguística a respeito das mudanças verificadas na língua indígena e do papel que a introdução do português (percebida através de empréstimos e codeswitching) pode ter em seu deslocamento, o que pode ser verificado pelo forte discurso de preocupação em manter a "linguagem original", "sem misturar".

Esperamos somar esforços para atender aos anseios do povo Xerente de ter, ao mesmo tempo, meios de conviver e competir por espaços sociais em pés de igualdade com a sociedade não indígena circundante e de conservar suas formas particulares de recortar e se inserir na realidade, marcadas na(s) sua(s) língua(s) e cultura(s).

\section{CONSIDERAÇÕES FINAIS}

Na prática, a pesquisa sobre o comportamento do code-switching e empréstimos na comunidade de fala Xerente oferece subsídios para o planejamento e implementação de políticas linguísticas condizentes com tal realidade sociolinguística. A cooficialização da língua Xerente em Tocantínia (em 2012) abre novas possibilidades para isso. A pequena cidade, onde estavam matriculadas 182 crianças indígenas em 2012, abriga aproximadamente um décimo da população Xerente, além dos demais que transitam por lá diariamente. Talvez esse seja o lugar propício, além das aldeias Xerente, para uma virada nas políticas linguísticas e socioculturais homogeneizantes e monolinguistas e onde haja práticas verdadeiramente bilíngues, interculturais, diferenciadas e específicas.

Ademais, as análises (especialmente de contraexemplos) colaboram para o desenvolvimento científico na área das ciências da linguagem e constante reelaboração das discussões (sócio)linguísticas acerca do contato entre línguas e dos modelos teóricos utilizados para tal tarefa. 
LOANWORDS AND CODE-SWITCHING IN AKWẼ XERENTE / PORTUGUESE:

CONTRIBUTIONS TO THE SOCIOLINGUISTICS, THE INDIGENOUS EDUCATION AND

THE AKWẼ PEOPLE

\section{ABSTRACT}

This paper analyzes the occurrence of loanwords and code-switching in the speech community Akwẽ-Xerente (Jê), considering its linguistic and extralinguistic aspects. The contact phenomena are analyzed in light of Speech Ethnography (Hymes, 1972), the 4-M model (Myers-Scotton; JAKE, 2000), the Markedness Model and MLF, developed by Myers-Scotton (1993a; 1993b; 2002). The analyses indicate the behavior of sensible phenomena to sociolinguistics variables and identified speech events. They are also conducted in order to contribute to the science of language, to a critical reflection of Xerente people about their own reality and for indigenous education.

Keywords: Sociolinguistics, Akwẽ Xerente language, Portuguese language, Code-switching, Indigenous education.

PRÉSTAMOS LINGÜÍSTICOS Y CODE-SWITCHING EN AKWẼ XERENTE/PORTUGUÉS: CONTRIBUCIONES PARA LA SOCIOLINGÜÍSTICA, PARA LA EDUCACIÓN INDÍGENA Y PARA EL PUEBLO AKWẼ

\section{RESUMEN}

Este artículo analiza la ocurrencia de préstamos lingüísticos y code-switching en la comunidad de habla Akwẽ-Xerente (Jê), considerando sus aspectos lingüísticos y extralingüísticos. Los fenómenos de contacto son analizados a la luz de la Etnografía de la comunicación (HYMES, 1972), del modelo 4-M (MYERS-SCOTTON; JAKE, 2000), del Markedness Model y del MLF, desarrollado por MYERS-SCOTTON (1993a; 1993b; 2002). Los análisis muestran el comportamiento de los fenómenos sensibles a las variables sociolingüísticas y eventos de habla identificados. También están dirigidos en el sentido de su contribución para las ciencias del lenguaje, para la reflexión crítica del pueblo Xerente sobre su propia realidad y para la educación indígena.

Palabras-clave: Sociolingüística, Lengua Akwẽ Xerente, Lengua portuguesa, Code-switching, Educación indígena. 


\section{Notas}

1 Para uma visão mais abrangente, veja Giraldin e Silva (2002) e Farias (1990).

2 A transcrição ortográfica privilegiou uma aproximação à produção fônica para uma melhor visualização das variedades do português e da língua Xerente utilizadas em cada exemplo. As correspondências entre grafemas e fonemas/fones são representadas, neste caso, por símbolos do IPA (International Phonetic Alphabet).

3 De qualquer forma, um estudo de frequência (MESQUITA, 2009) e uma observação mais diacrônica (de aproximadamente dez anos) durante a pesquisa etnográfica nos permite apontar alguns empréstimos do português consolidados na língua Xerente.

4 Uma revisão mais detalhada pode ser encontrada em Mesquita (2015a)

5 Veja discussão em Mesquita, 2015a.

6 Siglas e abreviações utilizadas na transcrição dos dados: 1=primeira pessoa; $2=$ segunda pessoa; $3=$ terceira pessoa; $\mathrm{ALA}=$ alativo; $\mathrm{CIT}=$ citacional; $\mathrm{DAT}=$ dativo; $\quad \mathrm{DEM}=$ demonstrativo; $\quad \mathrm{DIM}=$ diminutivo; $\quad \mathrm{DIR}=$ diretiva; ENF=enfático; $\quad$ ERG=ergativo; $\quad \mathrm{Ev}=$ =videnciativo; $\quad \mathrm{FUT}=$ futuro;

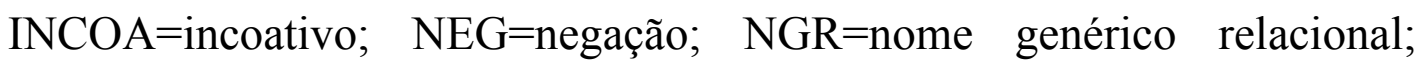
$\mathrm{NMZ}=$ Nominalizador; $\mathrm{NSG}=$ não singular; $\mathrm{PARTT}=$ partitivo; $\mathrm{PAS}=$ passado; $\mathrm{PERF}=$ perfectivo; $\mathrm{POSP}=$ posposição; $\mathrm{R}=$ prefixo relacional (R1,R2 e R3); REPET=Repetição (repetidamente); $\mathrm{SING}=$ singular; $\mathrm{TC}=$ termo de classe.

7 Em 2011 se formou a primeira turma (de dez) professores Akwẽ no curso, em nível superior, de Licenciatura Intercultural para professores indígenas da Universidade Federal de Goiás e, desde então, novas turmas são formadas todos os anos com o retorno de dezenas de professores para atuar nas aldeias.

\section{REFERÊNCIAS}

BRAGGIO, S. L. B. Aquisição e uso de duas línguas: variedades, mudança de código e empréstimo. Boletim da Associação Brasileira de Linguística, n. 20, p. 139-172, 1997. 
. Um Estudo Tipológico Sociolinguístico dos Xerente Akwe: Questões de Vitalização. In: AGUIAR, O. B. (Org.). Região, Nação, Identidade. Goiânia: AGEPEL, Instituto Centro-Brasileiro de Cultura, 2005. p. 165-183.

. As diferentes situações sociolinguísticas e os tipos de empréstimos na adição do português ao xerente akwén: fatores positivos e negativos. LIAMES, v. 12, p. 157-177, 2012.

BRAGGIO, S. L. B.; SOUSA FILHO, Sinval Martins de. Questionamentos diante do desafio da inclusão dos povos indígenas brasileiros no atual cenário: os Xerente. Revista Signótica. Goiânia, v. 18, n. 2, p. 215-230, jul./dez., 2006. BULLOCK, B. E.; TORIBIO, A. J. Themes in the study of code-switching. In: . The Cambridge Handbook of Linguistic Code-switching. UK and New York: Cambridge University Press, 2009. p. 01-17.

CALlAHAN, Laura. Spanish/English Codeswitching in a Written Corpus. Amsterdam/ Philadelphia: John Benjamins Publishing Company, 2004.

COTRIM, R. G. P. M. Romwaihku Akwẽ-Xerente, Português, English: Diálogo Intercultural no Ensino-Aprendizagem do Inglês (L3) para professores indígenas. 2011. Dissertação (Mestrado em Letras e Linguística) - Faculdade de Letras, Universidade Federal de Goiás, Goiânia, 2011.

GARDNER-CHLOROS, P. Code-switching. New York: Cambridge University, 2009.

GIRALDIN, O.; SILVA, C. A. Ligando Mundos: relação entre xerente e a sociedade circundante no século XIX. Boletim do Museu Paraense Emílio Goeldi, Série Antropologia, v. 18, n. 1, p. 43-58, 2002.

GROSJEAN, F. Life With Two Languages: an introduction to bilingualism. Harvard University Press, 1982.

HYMES, D. Toward ethnographies of communication: the analysis of communicative events. In: GIGLIOLI, P. P. (Ed.). Language and social context. Harmonds worth: Penguin Books, 1972 [1964]. p. 21-43.

KRIEGER, W. B.; KRIEGER, G. C. Dicionário escolar: Xerente-PortuguêsXerente. Rio de Janeiro: Junta das Missões Nacionais da Convenção Batista Brasileira, 1994.

MELO, V. M. C. Diversidade, meio ambiente e educação: uma reflexão a partir da sociedade Xerente. 2010. Dissertação (Mestrado em Ciências do Ambiente) - Universidade Federal do Tocantins, Palmas, 2010. 
MESQUITA, R. Empréstimos do Português em Xerente Akwe. Dissertação (Mestrado em Letras e Linguística) - Faculdade de Letras, UFG, Goiânia, 2009.

. Code-switching em Akwẽ-Xerente/Português. Tese (Doutorado em Letras e Linguística) - Faculdade de Letras, Universidade Federal de Goiás, Goiânia, 2015a.

. Indígenas em contexto urbano, conflitos socioculturais e linguísticos: o exemplo dos Akwẽ-Xerente. Revista de Ciências HUMANAS. Florianópolis, v. 49, n. 2, p. 143-162, 2015 b.

MESQUITA, R.; SILVA, J. I. O certo seria falar só em xerente mesmo, sem misturar: atitudes de jovens Akwẽ em relação ao code-switching. Revista Todas as Letras, 2016. No prelo.

MYERS-SCOTTON, C. Duelling Languages: Grammatical Structure in Codeswitching. Clarendon Press: Oxford, 1993a.

. Social Motivations for Codeswitching: evidence from Africa. New York: Oxford University Press, 1993b.

. Contact Linguistics: bilingual encounters and grammatical outcomes. Oxford: Oxford University Press, 2002.

; JAKE, J. L. Four types of morpheme: evidence from aphasia, code switching, and second-language acquisition. Linguistics, v. 38, p. 1053-1100, 2000.

REZENDE, T. F. Ensino intercultural de português para indígenas. In: BARROS, Déborah Magalhães de; SILVA, Kleber Aparecido; GALVÃO, Vânia Casseb. (Org.). O ensino em quatro atos: interculturalidade, tecnologia de informação, leitura e gramática. Campinas-SP: Pontes, 2015. p. 79-129.

SEDUC-TO. Ata de Reunião do Conselho Indígena - Povo Xerente. Tocantínia: Secretaria de Educação do Estado do Tocantins, 2012, mimeo.

SOUSA FILHO, S. M. Aspectos Morfossintáticos da Lingua Akwén-Xerente (Jê). Tese (Doutorado em Letras e Linguística) - Faculdade de Letras, UFG, Goiânia, 2007.

Submetido em 28 de maio de 2015.

Aceito em 10 de julho de 2016.

Publicado em 23 de novembro de 2016. 